\title{
Imaginário e contágio psíquico
}

\author{
Malena Contrera \\ Doutora; Universidade Paulista, São Paulo, SP, Brasil \\ malenacontrera@uol.com.br \\ Leonardo Torres \\ Doutorando; Universidade Paulista, São Paulo, SP, Brasil \\ leosouzatorres@gmail.com
}

\section{Resumo}

O objetivo deste artigo é refletir, a partir de fatos relatados pela mídia, a questão do contágio psíquico (possessões coletivas), bem como relaciona-lo com os estudos do imaginário, compreendendo como os processos de empatia e mimese facilitam tais contágios e os quadros de possessão coletiva. Dessa forma, este artigo conclui que o contágio psíquico (possessões coletivas) são ações de conteúdos imaginários, os quais emergem do Inconsciente Coletivo, em momentos de forte comoção e afetação geral. $\mathrm{O}$ artigo tem como metodologia a coleta de dados e revisão bibliográfica, tendo como principais referenciais teóricos Carl G. Jung, Edgar Morin, Christoph Wulf, James Hillman, Frans de Waal, Rafael Lopez-Pedraza e Norval Baitello Júnior.

\section{Palavras-chave}

Imaginário. Contágio psíquico. Empatia. Mimese.

\section{Estranhos fenômenos sempre viram notícia - as possessões coletivas}

Notícias sobre fenômenos estranhos sempre são recebidas com enorme curiosidade, com risos - nervosos, às vezes -, com incredulidade por uns e com absoluta fé por outros. No entanto, o poder de fascínio que elas exercem é inegável, levando-nos a liberar as fantasias, a devanear sobre os acontecimentos, a exercitar a imaginação. Contudo, se nos debruçarmos sobre os relatos dos casos, veremos que eles sinalizam para algo mais complexo do que inicialmente podemos supor. Se olharmos mais de perto, alguns desses casos, popularmente chamados de possessão coletiva, são reveladores de aspectos relevantes aos estudos do imaginário, apontando para as relações existentes entre imaginário e contágio psíquico. 
Segundo o documentário "The town that nearly danced itself to death" (2016) da BBC e a Revista Galileu (2016), no ano de 1518, na cidade de Estrasburgo, na França, uma mulher chamada Frau Troffea iniciou passos de dança no meio de uma rua. Em uma semana, 34 indivíduos, mulheres, homens e crianças (MINDSHADOW, 2016), estavam contagiados pela dança que a mulher iniciara; em um mês, cerca de quatrocentos indivíduos ainda continuavam a dançar, tomando ruas adjacentes. Inicialmente, "[...] médicos e astrônomos da época concluíram que a epidemia era uma doença natural, causada por 'sangue quente' [...]" (GALILEU, 2016, doc. não paginado). Sem que se soubesse como lidar com a situação, consta que "[...] os habitantes saudáveis construíram palcos e levaram músicos ao local, pensando que a crise cessaria se fosse estimulada [...]" (GALILEU, 2016, doc. não paginado).

Entretanto, a estimulação por meio da música agravou o contágio, e a certo ponto da epidemia, os indivíduos já não dançavam mais por prazer, mas era impossível parar de dançar. Os relatos afirmam que, por não conseguirem parar de dançar, diversos indivíduos morreram de ataque cardíaco, derrame cerebral ou exaustão. A Revista Galileu (2016) ainda menciona que um jornal da época noticiou que cerca de quinze indivíduos morreram por dia durante esse estranho evento.

Figura 1 - Retrato da Epidemia de Dança em Estrasburgo, por Henricus Hondius

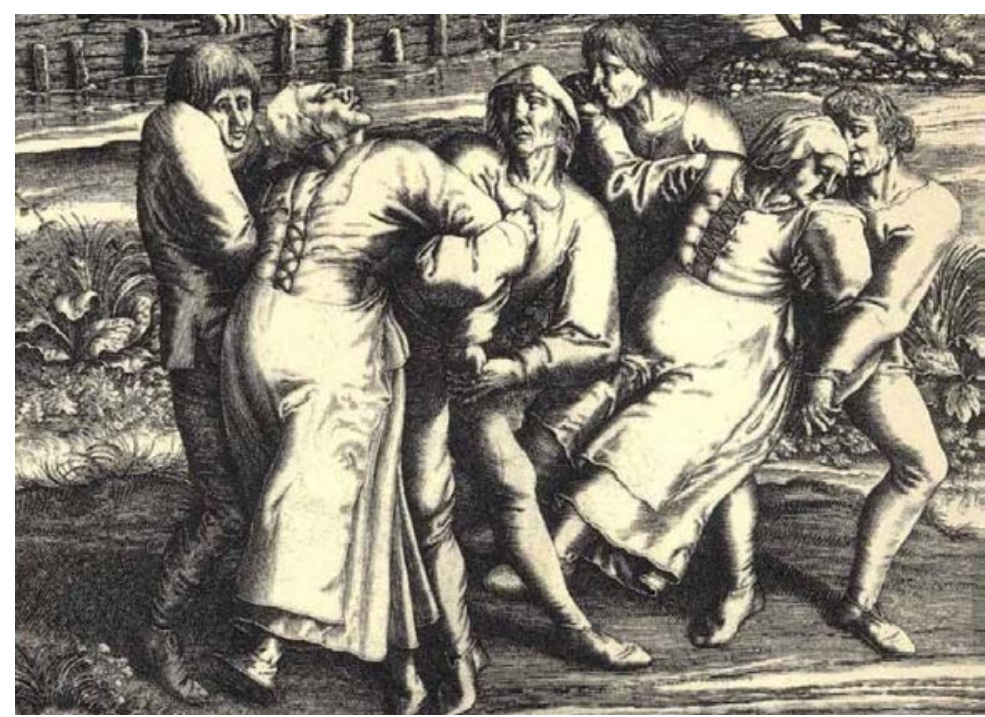

Fonte: GALILEU (2016).

Esse caso que poderia ser chamado de possessão coletiva, ocorrido em Estrasburgo, durou quatro meses, até cessar sem nenhuma causa aparente. Os indivíduos que sobreviveram voltaram a suas vidas cotidianas, enquanto "[...] especialistas discutiram se a epidemia era uma doença real ou um fenômeno social. As evidências acabaram apontando 
que a epidemia era uma espécie de contágio cultural [...]" (GALILEU, 2016, doc. não paginado). 0 termo "contágio cultural", escolhido para designar o ocorrido, não poderia ser mais feliz, e se fôssemos buscar um nome mais apropriado, a partir do que hoje conhecemos sobre Psicologia Arquetípica, poderia ser designado por contágio psíquico.

Esse não foi, no entanto, um caso solitário sobre essa espécie de fenômeno. Segundo Bartholomew e Wessely (2002), entre os séculos XV e XIX, freiras de conventos europeus, conhecidos por uma severa austeridade e rotina, começaram a apresentar em certos momentos o que na época foi chamado de "possessões demoníacas". Tais episódios de possessão, assim como o exemplo acima citado, duravam meses e cessavam sem qualquer explicação. Um deles é bem interessante, pontua Hecker (1844, p.127), "[...] as freiras miavam juntas por várias horas todos os dias, por um certo tempo [...]".

Bartholomew e Wessely (2002) ainda mencionam que, na época, as freiras foram consideradas rebeldes e, em alguns casos, bruxas foram queimadas na fogueira. Elas ainda “[...] usavam linguagem obscena e blasfema e desenvolviam um comportamento lascivo: expor a genitália, esfregar partes íntimas ou empurrar os quadris para denotar relações falsas [...]" (CALMEIL, 1845; GARNIER, 1895; LOREDAN, 1912, p.75, tradução nossa). Os membros da comunidade frequentemente assistiam aos espetáculos em uma atmosfera diária de teatro, enquanto os padres tentavam exorcizar os demônios, sem muito sucesso (BARTHOLOMEW; WESSELY, 2002).

Há, também, relatos de um caso muito interessante, no qual um surto de riso começou em 30 de janeiro de 1962, na Tanzânia, na Vila de Kashasha (FOLHA DE S. PAULO, 2001; AMERICAN SCIENTIST, 1996; THE GUARDIAN, 2007; 2008), em um colégio interno para meninas. Três alunas começaram a rir, e o riso foi se espalhando, afetando entre 95 a 159 outras meninas, entre 12 e 18 anos. Os sintomas duraram apenas algumas horas em algumas pessoas, em outras, se prolongaram por até 16 dias. Os professores não foram afetados, mas o fato convulsionou a escola, que foi obrigada a fechar as portas em 18 de março de 1962, reabrindo em 21 de maio, para ser novamente fechada no final de junho.

Pensava-se que o fechamento da escola desse fim ao surto, mas, conforme os estudantes voltavam para suas casas, o surto de riso se espalhava por toda a aldeia de Nshamba. Entre o período de abril e maio de 1962, por volta de 217 pessoas tiveram ataques de riso ininterruptos na aldeia (ATLAS OBSCURA, 2016). Em junho, com a reabertura da escola, a epidemia se espalhou novamente, chegando a afetar 48 meninas de 
outra escola, próximo a Bukova, outra cidade da Tanzânia. Da mesma forma como veio, se foi, sem que ninguém tivesse conseguido diagnosticar o que de fato se passou.

Outro exemplo de contágio psíquico, mais atual, ocorreu em 2008, na Tanzânia Central. 0 portal The Guardian (2008) relata que alunas de uma sala de aula começaram a desmaiar subitamente. Cerca de 20 meninas, rapidamente, perderam a consciência e outros alunos foram tomados por soluços e gritos.

O portal The Guardian (2008) ainda traz outros exemplos de vertigens e desmaios, como o de 1965, em Blackburn, na Inglaterra, no qual diversas alunas desmaiaram durante as aulas matinais. Preocupados com o estado físico das alunas, os professores pediram-lhes para que se deitassem, no chão, ao longo de um corredor principal. Ao meio-dia, 141 alunos estavam experimentando tonturas, náuseas, espasmos e falta de ar.

Alguns casos são extremos e evidenciam o papel de imagens arquetípicas como, por exemplo, no caso relatado pelo portal de notícias G1 (2010a), em Versailles, na França, no qual, ao se levantar à noite para preparar a mamadeira de seu bebê, um homem foi confundido com o "diabo" pela sua mulher que o agrediu, logo em seguida, com uma faca. A mulher ainda gritou "o diabo, o diabo", acordando todos os moradores do apartamento, cerca de onze pessoas (adultos e crianças) que, por sua vez, afirmaram ter mesmo visto o diabo ao olhar para o homem. Para fugirem do tal diabo, saltaram pela janela do segundo andar, sofrendo traumatismos múltiplos. 0 bebê, arremessado pela janela, faleceu no hospital após os primeiros socorros (YOUTUBE, 2010). 0 que levaria a imaginação de tantos a enlouquecer dessa maneira e ao mesmo tempo?

Ao estudarmos os processos relativos à imaginação e ao imaginário, sempre nos deparamos com muito mais perguntas do que certezas, no entanto, fica evidente, nesse e em outros inúmeros fenômenos análogos, que estamos tratando de contágios psíquicos e, em alguns casos, de possessão psíquica por parte de conteúdos do inconsciente coletivo, conteúdos que integram o que chamamos de imaginário cultural. Carl G. Jung sempre considerou com muito cuidado as possibilidades das possessões coletivas, pontuando que: “[...] quando a temperatura afetiva se eleva para além desse nível, a razão perde sua possibilidade efetiva, surgindo em seu lugar slogans e desejos quiméricos, isto é, uma espécie de possessão coletiva que, progressivamente, conduz a uma epidemia psíquica [...]" (JUNG, 1991, p. 2).

0 fato é que longe de serem processos do passado ou típicos de sociedades vitorianas e puritanas, nas quais a histeria podia sempre ser apontada, há algo nesses casos 
de inexplicável exclusivamente pelo viés da razão; não se pode considerar que sejam meras convulsões sociais. De fato, Jung nos lembra que "[...] há umas cinquenta gerações éramos, por assim dizer, simplesmente primitivos. A camada de cultura, essa simpática pátina, seria portanto extraordinariamente fina e tênue, comparada às camadas primitivas da psique, poderosamente desenvolvidas [...]" (JUNG, 2011a, p. 20).

Aqui no Brasil, em Itatira, no interior do Ceará, em junho de 2010, alguns estudantes entraram em transe, na escola, durante uma aula, debatendo-se e desmaiando, afirmando terem visto o espírito de um ex-aluno, morto há sete anos (G1, 2010b). Pode-se considerar que não se tratava de uma morte tão recente, de alguém que fosse do convívio diário da geração dos alunos, para afetá-los de modo tão intenso. Na sequência, as aulas foram suspensas, porque 25 alunas apresentaram comportamento agressivo, sendo hospitalizadas. A solução encontrada pela comunidade foi chamar um padre e parapsicólogo para fazer uma palestra, na qual ele atribuiu tudo a um caso de histeria/possessão coletiva. Nomear as coisas não é, necessariamente, compreendê-las ou acolher o sentido do qual elas são portadoras.

Jung (2011c), que tratou longamente desse tema, ao fazer uma análise sobre os fenômenos do Fascismo e do Nazismo na Europa do século XX, não reduziu sua análise ao diagnóstico de uma histeria das massas, mas buscou refletir quais os processos, os deuses e os demônios que se apresentavam por meio delas, evidenciando a ação dos conteúdos do imaginário nesses fenômenos. Sua análise abriu as portas para que outros psicólogos ${ }^{1}$ começassem a olhar para os fenômenos culturais mais predispostos a compreender como as placas tectônicas do inconsciente coletivo se mexem, fugindo da saída fácil do diagnóstico de "histeria coletiva".

Avaliando mais de perto, encontram-se diferentes elementos que integram a dinâmica dos contágios psíquicos coletivos - especialmente, quando temos a ação de um conteúdo do imaginário, de forma a rebaixar a consciência a ponto de podermos considerar um caso de possessão, submetendo-a à ação de conteúdos do inconsciente coletivo, ou arquétipos ${ }^{2}$, como designou Carl Gustav Jung (2011c)-, ou ainda o importante papel que as disposições empáticas e miméticas desempenham nos contágios psíquicos coletivos.

\footnotetext{
1 São muitos os casos de pós-junguianos que se ocuparam dessas análises, mas julgam-se especialmente felizes as análises feitas por James Hillman e Rafael López-Pedraza, ao longo de suas obras.

2 “Os arquétipos são de certa forma os fundamentos da psique consciente ocultos na profundidade ou, usando outra comparação, suas raízes afundadas não só na terra, em sentido estrito, mas no mundo em geral. Os arquétipos são sistemas de prontidão que são ao mesmo tempo imagens e emoções" (JUNG, 2011c, p. 40).
} 
Compreender de que forma esses contágios se dão alarga a discussão relativa aos fenômenos das massas. Desloca a atenção para o momento contemporâneo, no qual as massas, como tradicionalmente eram compreendidas, dissolvem-se, enquanto processos rizomáticos tomam seu lugar.

$\mathrm{Na}$ era das redes, em que cada nodo abriga potencialmente uma outra rede e em que as redes se entrelaçam de maneira complexa e não causal (CAPRA, 1997), problematizar o conceito de rede para pensar os fenômenos culturais, buscando por uma noção de rede mais complexa e menos tecno-funcional, nos aproxima, inevitavelmente, do Inconsciente Coletivo, como proposto por Jung.

É nesse sentido que não se pode considerar superados os fenômenos das massas, ainda que revisitemos toda a teoria sobre a qual suas análises se assentem até o final do século XX, sendo prudente não menosprezarmos os movimentos coletivos e o potencial de ressurgimento de um Leviatã, que agora se ergue de uma nova maneira.

\section{Contágio psíquico, empatia e mimese}

Estudando os processos miméticos e sua força na geração de comportamentos e crenças e no estabelecimento de formas diversas de sociabilidade, esbarramos na profunda relação existente entre mimese e contágio psíquico. Carl G. Jung já considerava a pertinência dessa relação ao afirmar que:

O homem possui uma faculdade muito valiosa para os propósitos coletivos, mas extremamente nociva para a individuação: sua tendência à imitação. A psicologia social não pode prescindir da imitação, pois sem ela seriam simplesmente impossíveis as organizações de massa, o Estado e a ordem social. A base da ordem social não é a lei, mas a imitação, este último conceito abarcando também a sugestionabilidade, a sugestão e o contágio mental. Podemos constatar diariamente como se usa e abusa do mecanismo da imitação, com o intuito de chegar-se a uma diferenciação pessoal: macaqueia-se alguma personalidade eminente, alguma característica ou atividade marcantes, obtendo-se assim uma diferenciação externa, relativa ao ambiente circundante. Poder-se-ia dizer que então, como que por castigo, intensifica-se a semelhança com o espírito do ambiente, a ponto de chegar-se a uma identificação compulsiva inconsciente com o mesmo (JUNG, 2011b, p.43-44).

Esse estado de "identificação compulsiva" com o ambiente social é o que podemos atribuir ao contágio psíquico a partir da ação da mimese. Mais do que a mimese que se desenvolve a partir do desejo e da projeção libidinal sobre um objeto (GIRARD, 2011), sabemos que a mimese é um processo central na constituição de sociabilidade (WULF; 
GEBAUER, 2004), e que o próprio vínculo ${ }^{3}$ não se desenvolve sem que a mimese tenha agido na geração de uma predisposição à criação de um campo comum. A própria comunicação não pode prescindir da mimese que, por sua vez, se desenvolve a partir das capacidades empáticas presentes nos seres humanos, mas não apenas neles (CONTRERA, 2014). A empatia nos torna assimiláveis e assimiladores, e a mimese gera padrões de similitude que formalizam e comunicam pelo viés performático e estético nossas afinidades, com quem sintonizamos. Esses processos não devem ser confundidos com concordância ideológica ou obediência e seriam mais bem compreendidos como sendo sincronizações vitais, considerando ainda que quase todos não são conscientemente controlados.

Por isso, não nos surpreende que haja um processo mimético tão intenso nos processos de contágio psíquico, especialmente, nos grandes centros urbanos ou em condições de intensa convivência social e de grande proximidade física, como no caso das escolas ou dos conventos dos casos acima citados. Onde há a convivência compulsória, onde a sociabilidade aparece como um imperativo, então ali, entra em cena, mais intensamente, o comportamento mimético, na tentativa de criar um ambiente significativo, ou ao menos suportável, de interação.

As formas econômicas e ideológicas presentes na cultura de massas, conforme apontada por E. Morin (1990), souberam utilizar bem, em todo o século XX, os elementos estéticos para a geração de processos miméticos por meio da mídia eletrônica. Predispondonos aos constantes apelos estéticos da mídia, tornou-nos mais fascináveis do que jamais fomos ${ }^{4}$. Se por um lado somos levados a gerar mimese por meio de recursos estéticos, por outro, nossas capacidades empáticas se fragilizam. Blindamo-nos para a alteridade e para o que diverge de nossos padrões estéticos pré-estabelecidos, já que, como sabemos (WAAL, 2012), nos humanos a empatia é seletiva.

O interessante, nos casos acima citados, é notar quais os elementos, ou ainda, os comportamentos que surgem como "comuns" nesses momentos dos surtos: vertigens, desmaios, corpos em convulsão erótica, dança compulsiva, visões de espíritos, comportamentos animais (o miado das freiras), o diabo (que ironicamente busca a mamadeira); conteúdos imaginais que apontam, claramente, para a ação de elementos arquetípicos do imaginário cultural.

\footnotetext{
3 O papel do vínculo é bem conhecido pela Psicologia e pela Etologia, e em nossa área foi aprofundado pelos estudos de Baitello Júnior (1997), que afirmou ser o vínculo condição primária para a comunicação.

${ }^{4}$ Sobre a relação entre fascínio, consumo e mimese, há dois textos que tratam, diretamente, de mimese, estética e consumo, feitos em parceria com Cristiane de Rossi Žovin (2014) e de Carlos Henrique Aiello (2015), presentes nas referências.
} 


\section{Possessão psíquica e a ação dos arquétipos}

Quando o contágio psíquico extrapola em muito qualquer traço de racionalidade, ou leva a ações extremas, das quais as pessoas provavelmente se envergonhariam se estivessem minimamente no controle consciente de suas ações, podemos considerar o quadro de possessão psíquica. Aqui, estamos quase sempre lidando com a aquilo que poderíamos chamar de ação dos "seres do espírito", como E. Morin (1992) escolhe chamar os seres do imaginário. Sabemos que esses seres do espírito mantêm conosco uma relação de mútua imbricação, nós os possuímos e eles nos possuem; na maioria das vezes, em que pensamos possuí-los, são eles que, na realidade, nos possuem. E, às vezes, esse possuir se literaliza.

É por meio da ação dos arquétipos que os seres do imaginário, que os integram, exercem seu poder sobre nós. Conhecendo bem o fato de que os arquétipos sejam formas $a$ priori, ou ainda "[...] imagens primordiais, virtuais em todo o espírito humano, matrizes universais do inconsciente coletivo [...]" (MORIN, 1992, p. 96), Morin bem sabia da inevitabilidade de sua ação no espírito humano: "[...] eles comandam e controlam os nossos sonhos e os nossos mitos. Embora não existam independentemente de nós, nós dependemos deles porque trazemos conosco as suas exigências e as suas tiranias [...]" (MORIN, 1992, p. 96).

Essas exigências e tiranias beiram todo tipo de grotesco, de horror, de cômico, sendo, de fato, uma excelente expressão daquilo que se pode chamar de patologia, a incontrolável "sofrência" humana; são exigências vindas dos escondidos da alma, daquilo que foi renegado, abafado, emudecido, perfazendo o que C. G. Jung chamaria de Sombra aquele indesejável que vemos nos outros, mas não em nós mesmos, aquilo que insistimos em negar e reprimir.

James Hillman (1993) usa uma metáfora feliz ao dizer que todos temos o quarto escondido, a ala dos fundos da alma, no qual se debatem os seres sombrios do imaginário, uma espécie de "desordem crônica". No entanto, nossos demônios pessoais, normalmente, não viram notícia como viram os monstros coletivos (até mesmo, porque há um século ao menos temos a clínica psicológica para deles se ocupar), os que se movem com o corpo das massas, das hordas que, ao se coagularem em coletivos, nos jogam sempre ao primitivo, trazendo à tona algo de visceral. 
E eis que a Sombra coletiva quer dançar, miar, quer desfalecer, mostrar os buracos do corpo por onde vemos as vísceras, traz de volta os diabos escondidos nos apartamentos das boas famílias cristãs.

Interessante notar que notícias tão afastadas no espaço e no tempo, como as que apresentamos acima, tenham em comum as entranhas, o corpo. Esse renegado de longa data que sempre incomodou as religiões monoteístas que veem nele, desde seus primórdios, a resistência aos ditames do pecado, o que insiste em pulsar para além de toda a culpa implantada pelos programas disciplinares que vão desde os preceitos religiosos mais comuns ao elogio sistemático ao virtual. A relação entre monoteísmo, virtual, imaterial e o capital não é nova e a partir de M. Weber (2004) já a temos mapeada e nomeada como desencantamento do mundo (CONTRERA, 2010), esse mesmo desencantamento que desencantou centralmente o corpo, que o subjugou a uma visão mecânica e funcional, que renegou ao corpo sua dimensão sagrada.

O grotesco ainda carrega algo de atávico quando se manifesta, mas a Sombra coletiva, quando menos grotesca e corporal, desenvolve delírios de grandeza, crenças de pureza e superioridade, como se um Apolo enlouquecido quisesse se vingar por sermos tão humanos. Essa foi a triste cena do nazismo (JUNG, 2011c), e esse é o atual delírio de superioridade e grandeza que renasce hoje nos discursos das direitas políticas em todo o mundo, sempre acompanhados do estímulo - velado ou não - à violência. Sabemos bem como violência e contágio psíquico, aliás, caminham tão bem juntos.

Sobre essa relação Jung comentou que: “[...] todo indivíduo é, inconscientemente, pior em sociedade do que quando atua por si só. 0 motivo é que a sociedade o arrasta e na mesma medida o torna isento de sua responsabilidade individual [...]" (JUNG, 2011b, p. 41).

O claro rebaixamento da consciência provocado pelo mergulho na coletividade foi apontado por ele, quando disse que “[...] um grupo numeroso de pessoas, ainda que composto de indivíduos admiráveis, revela a inteligência e moralidade de um animal pesado, estúpido e predisposto à violência [...]" (JUNG, 2011b, p. 41).

Em um mundo cada vez mais superpovoado e que se aproxima das sociedades entômicas, como bem lembrou Baitello Júnior (2014), não seria irrelevante entender melhor os processos de contágio psíquico. Eles têm uma força insuspeita para nós.

Os enxames, ao contrário das colunas em marcha, não exigem sargentos ou cabos; encontram infalivelmente seu caminho sem a interferência desagradável dos escalões superiores com suas ordens do dia. Ninguém lidera os enxames para os campos floridos; ninguém precisa manter os 
membros do enxame sobre controle, pregar para eles, tocá-los adiante pela força, com ameaça ou forçando-os no caminho. Quem quiser conservar um enxame de abelhas num curso desejável se dará melhor cuidando das flores no campo, não adestrando cada abelha (BAUMAN, 2013, p. 54-55).

Os elementos atratores do contágio psíquico são em sua maioria estéticos, como aponta Bauman, mas os elementos impulsores certamente são de ordem arquetípica e imaginária.

Seria desejável entender como agem as possessões dos conteúdos do imaginário mediático. Temos estudado os virais da Internet, mas possivelmente eles sejam a mera ponta de um iceberg em direção ao qual nosso navio desliza. A Mediosfera nem sempre abriga um Dionísio que quer dançar, um Diabo que alimenta, ou ainda a vertigem de Pã. Os seres da Mediosfera nos possuem de forma menos tragicômica, menos poética, e não temos ideia de quais "deuses da mídia" se levantarão e nos engolirão nos próximos anos, ou qual novo vento perfumado cativará esteticamente a multidão de abelhas. Será preciso olhar nos espelhos que refletem as novas medusas de nossa época e ter a coragem de ver neles o humano demasiadamente humano que os conteúdos do imaginário abrigam.

\section{Referências}

AMERICAN SCIENTIST. Laughter. [S.l.]: 1996. Disponível em: <http://bit.ly/2kM10Pi>. Acesso em: 06 fev. 2017.

ATLAS OBSCURA. The 1962 laughter epidemic of tanganyika was no joke. [S.l.]: 2016. Disponível em: <http://bit.ly/2em3bh1>. Acesso em: 07 fev. 2017.

BAITELLO JÚNIOR, N. O animal que parou os relógios. São Paulo: Annablume, 1997.

BAITELLO JÚNIOR, N. A era da iconofagia: reflexões sobre imagem, comunicação, mídia e cultura. São Paulo: Paulus, 2014.

BARTHOLOMEW, R. E.; WESSELY, S. Protean nature of mass sociogenic illness: from possessed nuns to chemical and biological terrorism fears. The british journal of psychiatry, [S.l.], n. 180, v. 4, p. 300-306, abr. 2002. Disponível em: <http://bit.ly/2iFoHjf>. Acesso em: 11 jan. 2017.

BAUMAN, Z. A cultura no mundo líquido moderno. Rio de Janeiro: Zahar, 2013.

BBC. The town that nearly danced itself to death. [S.l.]: 2016. Disponível em: <http://bbc.in/2f0JT20>. Acesso em: 11 jan. 2017.

CALMEIL, L. F. De la folie, considerée sous le point de vue pathologique, philosophique, historique et judiciaire: on madness, consideration on the point of pathology, philosophy, history and justice. Paris: Baillière, 1845. 
CAPRA, F. A teia da vida: uma nova compreensão científica dos sistemas vivos. São Paulo: Cultrix; Amana-Key, 1997.

CONTRERA, M. S. Mediosfera: meios, imaginário e desencantamento do mundo. São Paulo: Annablume, 2010.

CONTRERA, M. S. Simpatia e empatia - mediosfera e noosfera. In: BAITELLO JÚNIOR. N.; WULF, C. (Org.). Emoção e imaginação: os sentidos e as imagens em movimento. São Paulo: Estação das Letras e Cores, 2014.

CONTRERA, M. S.; AIELLO, C. H. A imagem midiática dos padrões estéticos nos fenômenos da adultescência e infantescência. Revista Tríade, Sorocaba, v. 3, 2015.

CONTRERA, M. S.; ZOVIN, C. de R. Boneca não fala? O silencio mimético na sociedade mediática. Revista Interin, Curitiba, v. 18, 2014.

FOLHA DE S. PAULO. Epidemia de riso durou dois anos e meio na África. [S.I.]: 04 jan. 2001. Disponível em: <http://bit.ly/2kMfNVk>. Acesso em: 06 fev. 2017.

G1. Visão do 'diabo' faz 11 pularem pela janela na França. [S.l.]: 23 out. 2010a. Disponível em: <http://glo.bo/2jiJeLo>. Acesso em: 11 jan. 2017.

G1. Alunos são socorridos em hospital depois de 'falar com espírito' no Ceará. [S.l.]: 2010b. Disponível em: <http://glo.bo/2kfqMmM>. Acesso em: 06 fev. 2017.

GALILEU. 0 que causou a estranha epidemia de dança de 1518. [S.l.]: 2016. Disponível em: <http://glo.bo/2ehSVGi>. Acesso em: 11 jan. 2017.

GARNIER, S. Barbe buvee, en religion, soeur sainte-colombe et la prétendue possession des ursulines d'auxonne. Paris: Felix Alcan, 1895.

GIRARD, R. Anorexia e desejo mimético. São Paulo: É Realizações, 2011.

HECKER, J. F. C. Epidemics of the middle ages. London: Sydenham Society, 1844.

HILLMAN, J. Cidade e alma. São Paulo: Studio Nobel, 1993.

JUNG, C. G. Presente e futuro. Petrópolis: Vozes, 1991.

JUNG, C. G. Civilização em transição. Petrópolis: Vozes, 2011a.

JUNG, C. G. 0 eu e o inconsciente. Petrópolis: Vozes, 2011b.

JUNG, C. G. 0 espírito na arte e na ciência. Petrópolis: Vozes, 2011c.

LÓPEZ-PEDRAZA, R. Ansiedade cultural. São Paulo: Paulus, 1997. 
LOREDAN, J. Un grand procès de sorcellerie au xviie siècle, l'abbé gaufridy et Madéleine de Demandolx (1600-1670) Paris: Perrin et Cie, 1912.

MINDSHADOW. L'epidémie dansante de Strasbourg. [S.l.]: 2016. Disponível em: <http://www.mindshadow.fr/epidemie-dansante-strasbourg/>. Acesso em: 11 jan. 2017.

MORIN, E. Cultura de massas no século XX. São Paulo: Forense-Universitária, 1990.

MORIN, E. 0 método 4. Lisboa: Publicações Europa-América, 1992.

THE GUARDIAN. Falling down. [S.l.]: 18 set. 2008. Disponível em: <http://bit.ly/2ifBVlZ>. Acesso em: 11 jan. 2017.

THE GUARDIAN. The outbreak of hysteria that's no fun at all. [S.l.]: 21 nov. 2007.

Disponível em: <http://bit.ly/2kM4coY>. Acesso em: 06 fev. 2017

WAAL, F. A era da empatia. São Paulo: Companhia das Letras, 2012.

WEBER, M. A ética protestante e o espírito do capitalismo. São Paulo: Companhia das Letras, 2004.

WULF, C.; GEBAUER, G. Mimese na cultura: agir social, rituais e jogos, produções estéticas. São Paulo: Annablume, 2004.

YOUTUBE. Visão do diabo faz 11 pularem da janela na França. [S.l.]: 2010. Disponível em: <https://youtu.be/ImPg5oE_zKg>. Acesso em: 11 jan. 2017.

\title{
Imaginary and psychic contagion
}

\begin{abstract}
The main goal is to think, based on facts already reported by the media, the question of psychic contagion (collective possessions) and relate it with the imaginary studies, to understand how the processes of empathy and mimesis facilitate the phenomenon of the psychic contagion and collective possession. In this way, this article concludes that the psychic contagion (collective possessions) are actions of imaginary contents, which emerge from the Collective Unconscious, in moments of strong commotion and general affectation. The main theoretical references are Carl G. Jung, Edgar Morin, Christoph Wulf, James Hillman, Frans de Waal, Rafael Lopez-Pedraza and Norval Baitello Júnior.
\end{abstract}

\section{Keywords}

Imaginary. Psychic contagion. Emphaty. Mimesis. 